\title{
Narrative review of assessing the surgical options for double outlet right ventricle
}

\author{
Antonio F. Corno ${ }^{1}$, Saravanan Durairaj ${ }^{2}$, Gregory J. Skinner ${ }^{2}$ \\ ${ }^{1}$ Houston Children's Heart Institute, Hermann Children's Hospital, University of Texas Health, McGovern Medical School, Houston, TX, USA; \\ ${ }^{2}$ East Midlands Congenital Heart Centre, University Hospitals of Leicester, Leicester, UK \\ Contributions: (I) Conception and design: AF Corno, GJ Skinner; (II) Administrative support: S Durairaj, GJ Skinner; (III) Provision of study \\ materials or patients: S Durairaj, GJ Skinner; (IV) Collection and assembly of data: All authors; (V) Data analysis and interpretation: AF Corno, GJ \\ Skinner; (VI) Manuscript writing: All authors; (VII) Final approval of manuscript: All authors. \\ Correspondence to: Antonio F. Corno, MD, FRCS (Glasgow), FETCS, FACC. Houston Children's Heart Institute, Hermann Children's Hospital, \\ University of Texas Health, McGovern Medical School, 6410 Fannin Street, UTPB 425.20, Houston, TX, 77030, USA. Email: tonycorno2@gmail.com.
}

\begin{abstract}
The individualized surgical approach in individuals with both arterial trunks arising from the morphologically right ventricle is dictated by the extreme morphological variability encountered in this setting, with each patient being unique. An individualized surgical approach has been designed to take account of the morphological variations, identifying the anatomy with the preoperative three-dimensional CT scan reconstruction. The key features have been considered the distance between tricuspid and pulmonary valves, the size and location of the interventricular communication, and the relationship between the outflow tracts. The surgical approach is tailored, whenever feasible, to create a connection between left ventricle and aorta, but primarily to achieve biventricular repair. Account has been taken of all available surgical options already reported in the literature, identifying the most suitable to provide the best outcomes for each unique morphology. To date, meaningful comparison between different reported surgical series has been difficult because of the marked variation of individual intracardiac morphology, and the lack of reports of specific surgical approaches for well-categorized groups of patients. Our approach, being tailored to the individual cardiac morphology, can be offered to any patient with this ventriculo-arterial connection. Given the difficulties of diagnosis, and the multiple therapeutic indications, very close collaboration between cardiologists and surgeons is indispensable for further progress in the understanding and management of this complex congenital cardiac lesion.
\end{abstract}

Keywords: Congenital heart defects; congenital heart surgery; double outlet right ventricle; morphology; threedimensional reconstruction; segmentation

Submitted Aug 04, 2020. Accepted for publication Nov 29, 2020.

doi: $10.21037 /$ tp-20-227

View this article at: http://dx.doi.org/10.21037/tp-20-227

\section{Introduction}

The first successful surgical repair of patients with double outlet right ventricle was reported in 1964, by those working in the Mayo Clinic (1). Extensive discussions regarding the anatomy and classification of this congenital heart defect followed the first surgical report, prompting one group of authors to posit that "we wish that years after the first successful repair of the malformation, the double outlet right ventricle should cease to be a morphogenic monster" (2).

The definition agreed by the combined committees of the Society of Thoracic Surgeons and the European Association of Cardiothoracic Surgery was for hearts in which both arterial trunks, in their greater part, are supported by the right ventricle. This approach recognized that the presence of bilateral infundibulums, or conuses, was not an essential criterion for diagnosis $(3,4)$. Irrespective of the precise definition, an extensive number 
of studies has now been published on both the morphology and categorization (5-14), as well as the available surgical approaches (15-39). In this regard, the recent advances in high resolution cross-sectional imaging, along with threedimensional anatomical reconstruction and printing, have also generated a series of articles highlighting their usefulness in planning the surgical approach for the repair (40-50). Others have evaluated the numerical simulations obtained with various geometric configurations $(51,52)$.

The multiple debates have resulted in the creation of many suggested subgroups within the individuals grouped together with the same ventriculo-arterial connection. This has made it difficult, on occasion, to appreciate which patient with a specific type of morphology underwent surgery with a particular surgical approach. Many years ago, Reploge and colleagues stated, with significant prescience, that "the definition of congenital heart defect is less important than how the malformation can be repaired, and the advantages of one type of repair over another cannot be ascertained unless one knows that each repair was performed for the same type of lesion" (53). In this review, we present a simplified approach to the lesion, based on the principles introduced long since by Lecompte (14,17-19,54). The rationale for this review in the context of what is already known is because in our opinion these principles provide the optimal method to determine the most appropriate surgical option for each individual patient, based on the underlying morphology as revealed by three-dimensional reconstruction. The source used for our literature search was PubMed (MedLine) with all articles published in English language with reports of surgery for patients with double outlet right ventricle.

We present the following article/case in accordance with the Narrative Review reporting checklist (available at http:// dx.doi.org/10.21037/tp-20-227).

\section{Pre-operative evaluation}

The key point identified for this review topic is that the choice of the optimal approach depends on two variables, namely the position of the interventricular communication, and the relationship of the arterial outlets. The optimal surgical approach, of course, is to connect the left ventricle in unobstructed fashion to the aorta, leaving the right ventricle in free communication with the pulmonary trunk, without needing to interpose a prosthetic conduit. When connecting the left ventricle to the aorta, the simplest method is to create a tunnel within the cavity of the right ventricle that channels the left ventricular blood towards the aortic valvar orifice. With very few exceptions, which will be discussed later, this is generally achievable, regardless of the position of the aortic valvar orifice. The critical point is to understand whether the right ventricle remains in free communication with the pulmonary trunk subsequent to construction of the interventricular tunnel. In this regard, the crucial feature is not the position of the aortic root, but rather the position of the pulmonary valvar orifice. In the normal heart, the outflow tracts of the right and left ventricles are not parallel. Due to the presence of the sub-pulmonary infundibular sleeve, the orifice of the pulmonary valve is far from the orifice of the tricuspid valve, and therefore the deoxygenated blood coming from the tricuspid valve must circumnavigate to reach the pulmonary valve (Figure 1).

When both outflow tracts arise from the right ventricle, as long as the pulmonary root is distant from the orifices of the atrioventricular valves, the distance between the atrioventricular valves and the aortic valvar orifice can increase without changing the relationship between the right and left outflow tracts. Thus, a more anterior location of the aortic root may lengthen the required sub-aortic tunnel, but will not preclude leaving an unobstructed pathway from the right ventricle to the orifice of the pulmonary valve (Figure 2).

Should the pulmonary root not possess a well-developed infundibulum, however, and is very close to, or even in continuity with, the atrioventricular valves, it may become impossible to maintain the normal relationships between the right and left ventricular outflow tracts. In this setting, the creation of an unrestricted tunnel from the left ventricle to the aorta can compromise the remaining connection between the tricuspid and pulmonary valves (Figure 3) This demonstrates that the feasibility of an intraventricular repair, in which the left ventricle is connected to the aorta, depends on the distance between the orifice of the tricuspid valve and the orifice of the pulmonary valve. Even when the interventricular communication is non-committed, good results have been recently reported, in patients above two years of the age, by placing a vascular prosthesis as an intraventricular conduit to rerouting the defect to the aorta, enlarging the defect and resecting hypertrophic muscular bands in the infundibular outflow tracts when necessary (55).

When taking account of these features, it becomes possible to separate hearts with both arterial trunks arising from the right ventricle into two categories. In the first group, the arrangement of the arterial roots is such that the distance between the tricuspid and pulmonary valves is at 


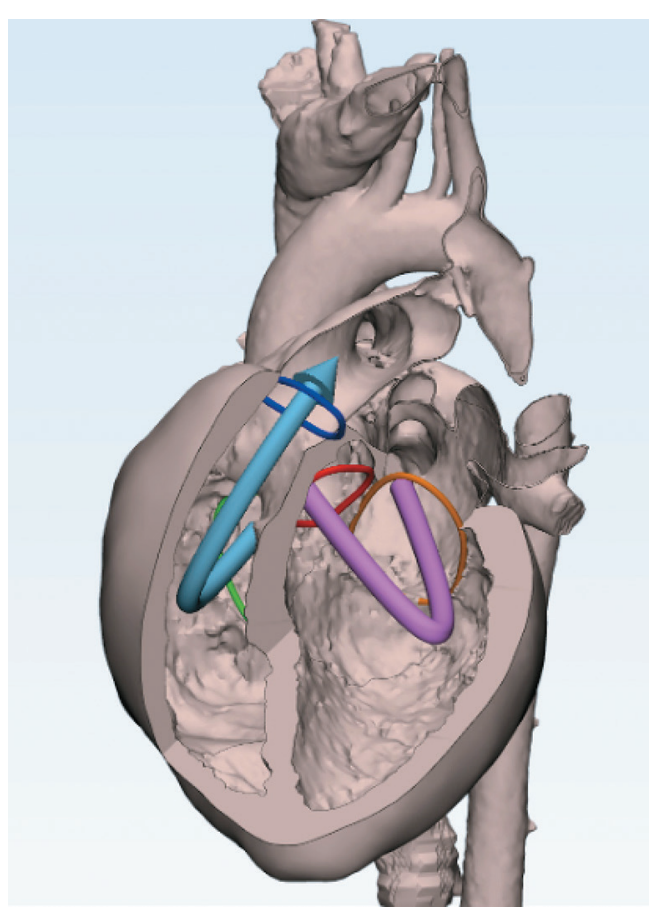

Figure 1 Three-dimensional reconstruction of a normal heart demonstrating the normal relationship of the left and right ventricular outflow tracts. Dark Blue, pulmonary valvar orifice; Red, aortic valvar orifice; Orange, mitral valvar orifice; Green, tricuspid valvar orifice; Pink arrow, left ventricular flow; Blue arrow, right ventricular flow.

least equal to the diameter of the aortic root. When this criterion is satisfied, it is usually possible to create the required unrestrictive tunnel to the aortic root without causing any obstruction to the residual connection between right ventricle and pulmonary valve. In the second group, the distance between tricuspid and pulmonary valves is less than the diameter of the aortic root. Recognition of this feature means that simple creation of a tunnel from the interventricular communication to the aortic root will not be feasible, and another surgical option will be required. In those fulfilling this second criterion, the position of the aortic valve may vary. Even should the aortic valve be in a near-normal position, creation of a simple intraventricular tunnel will not be feasible. In such individuals, the surgical option in the absence of a subpulmonary stenosis is ideally to create a tunnel to the pulmonary root, and then perform the arterial switch procedure (18) (Figure 4). When there is additional subpulmonary obstruction, the options may be repair as proposed by Rastelli $(56,57)$, the REV procedure (Figure 5) $(17,19,58-62)$, or the Bex-Nikaidoh
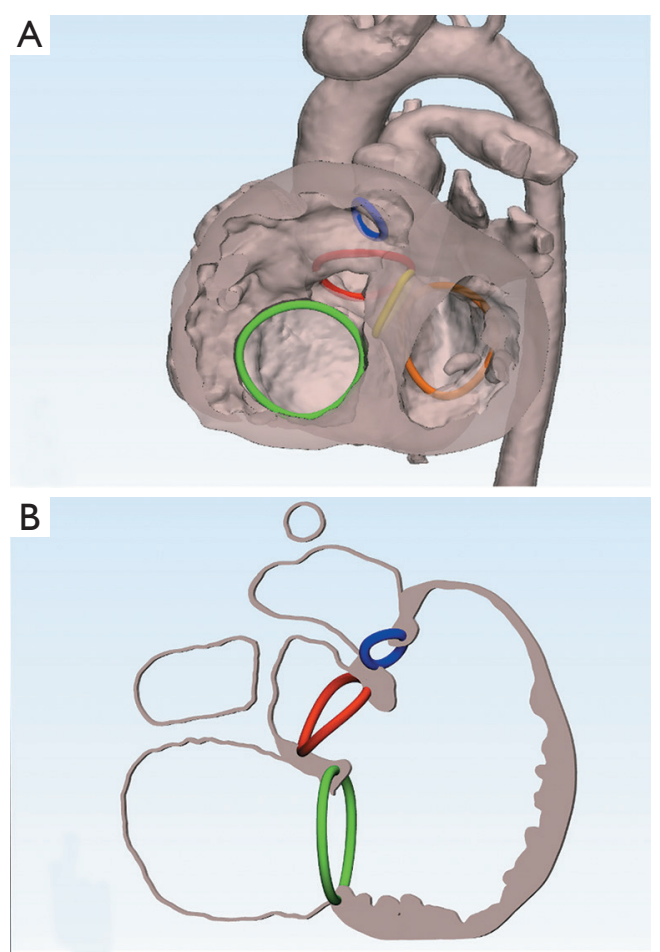

Figure 2 Three-dimensional reconstructions of DORV with the pulmonary valve distant from the atrioventricular valves. (A) A partially transparent three-dimensional reconstruction from a patient with double outlet right ventricle. The aortic valve orifice is displaced anteriorly, and arises exclusively from the right ventricle. Despite this, the relationship between the left and right ventricular outflows is preserved. (B) A section through the threedimensional model simulating the right anterior oblique view. This demonstrates the right ventricular cavity turning around the subaortic outflow tract. Dark Blue, pulmonary valvar orifice; Red, aortic valvar orifice; Orange, mitral valvar orifice; Green, tricuspid valvar orifice; Yellow, outline of the interventricular communication.

approach $(15,16,22-25,34,41)$.

The initial surgical step of the REV procedure, this being an acronym for "réparation à l'etage ventriculaire", $(17,19,58-62)$ is to make a generous resection of a segment of the ascending aorta, accompanied by the Lecompte manoeuvre of transposing the aorta posteriorly to the pulmonary trunk. Shortening the aorta reduces the radius of the curve between its ascending and descending portions, leaving space behind the sternum for the new right ventricular outflow tract. The outlet septum is then repositioned so as to create a straight and short tunnel from the left ventricle to the aorta. The procedure is 

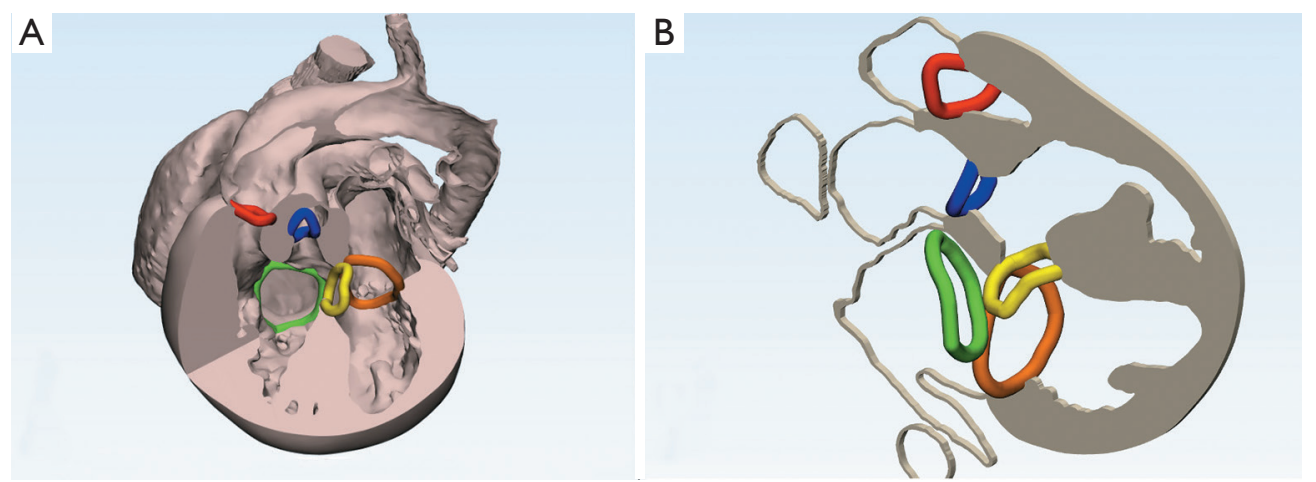

Figure 3 Three-dimensional reconstructions of DORV with the pulmonary valve in close proximity to the atrioventricular valves. (A) A three-dimensional reconstruction from patient with double outlet right ventricle where the aortic orifice is displaced more anteriorly, with the pulmonary valvar orifice closer to the atrioventricular valves. (B) A section through the model demonstrating the altered distance between the tricuspid and pulmonary valvar orifices. Dark Blue, pulmonary valvar orifice; Red, aortic valvar orifice; Orange, mitral valvar orifice; Green, tricuspid valvar orifice; Yellow, outline of interventricular communication.

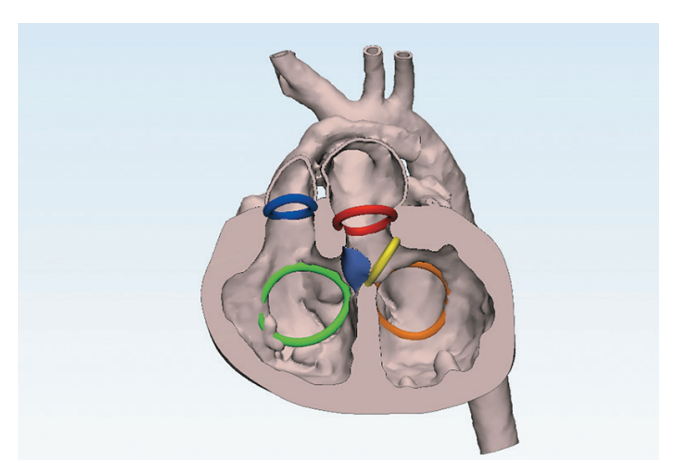

Figure 4 A three-dimensional reconstruction of a patient who has undergone an arterial switch repair of double outlet right ventricle subsequent to creation of an interventricular tunnel from the interventricular communication to the pulmonary root. Dark Blue, pulmonary valvar orifice; Red, aortic valvar orifice; Orange, mitral valvar orifice; Green, tricuspid valvar orifice; Yellow, outline of interventricular communication; Purple, position of the patch placed to connect the interventricular communication to the pulmonary root.

completed by reimplanting the pulmonary trunk directly on the right ventriculotomy, incorporating an anterior monocusp valved patch. The REV procedure is preferable to the Rastelli operation because of the potential for growth (17,19,52,57-62). It can, of course, also be performed in patients without right ventricular outflow tract obstruction. As the repair leaves a degree of pulmonary valvar regurgitation, it is preferable to use it in the presence of right ventricular outflow tract obstruction and low pulmonary vascular resistance.

The Bex-Nikaidoh procedure is now becoming

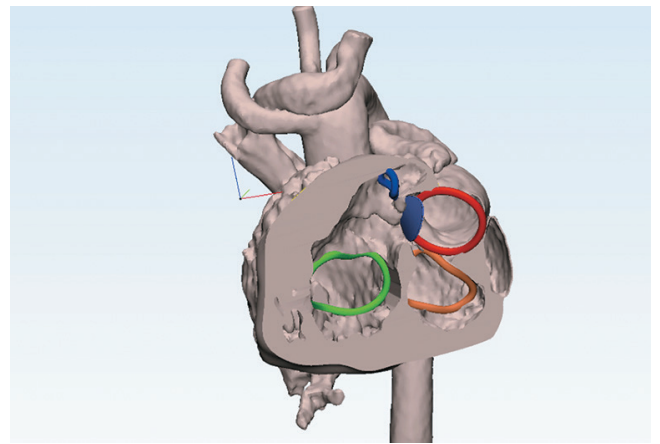

Figure 5 A three-dimensional reconstruction of a patient who has undergone the REV procedure. Dark Blue, pulmonary valvar orifice; Red, aortic valvar orifice; Orange, mitral valvar orifice; Green, tricuspid valvar orifice; Yellow, outline of interventricular communication; Purple, position of the patch placed to connect the interventricular communication to the pulmonary root.

increasingly popular $(15,16,22,24,25,34,41)$. The first step in this approach is to harvest the aortic root from the right ventricular outflow tract, with proximal transection of the pulmonary trunk. The obstructed subpulmonary outlet is then divided as to relieve any obstruction of the planned tunnel from the left ventricle. The liberated aortic root is translocated posteriorly, suturing it to the rim of the pulmonary root and the transected edges of the outlet septum. The anterior aspect of the newly constructed left ventricular outflow tract is then closed by placement of a patch, extending from the crest of the muscular ventricular septum, and closing the interventricular communication 
in the same time. The Lecompte maneuver is performed, with shortening of the ascending aorta so as to prevent posterior compression of the pulmonary arteries, as in the $\mathrm{REV}$ procedure. The procedure is completed by anastomising the hypoplastic pulmonary trunk to the right ventriculotomy, relieving any obstruction by placing an anterior transannular patch.

In both the above surgical procedures, REV and BexNikaidoh, it is essential to rule out any anomalous origin and/or course of the main coronary arteries, because this could dictate a different surgical approach.

There are, of course, other features that must be present so as to permit successful biventricular repair. Both ventricles need to be of adequate size, with normally functioning atrioventricular valves. It has to be feasible to close the remaining muscular part of the septum should there be additional septal defects, and there must be unobstructed distal flow to the systemic and pulmonary circulations.

\section{Ventricular size}

One of the criteria utilized in the past to define the suitability of a ventricular chamber to sustain either the systemic or pulmonary circulation was the size of its respective atrioventricular valve, which should be within 2 standard deviations of the normal values. Nowadays, segmentation of the ventricular cavities from electrocardiographicallygated cardiac computed tomographic scans, or magnetic resonance imaging data (42-52), allows for the calculation of the right and ventricular volumes indexed for the patient body surface area. Using three-dimensional anatomical reconstruction software, it is now possible to simulate the planned ventricular septation. Residual ventricular volumes can be estimated, allowing further assessment for the adequacy of a biventricular repair (Figure 6). Should either the left or right ventricular volumes be deemed inadequate, then consideration must be given towards a functionally univentricular or one-and-half ventricular repair (21,27,28,63-68). In borderline situations, it can be difficult to decide whether a high risk biventricular repair, either with a primary or a staged approach (69), is preferable to the alternative options $(21,27,63-68)$.

\section{Morphology and function of both atrioventricular valves}

When both arterial trunks arise from the right ventricle, the atrioventricular valves are frequently abnormal. Dysfunction of either valve can then be a contraindication to a biventricular repair. It is important, therefore, to evaluate the diameter of both atrioventricular valves. If they are greater than 2 standard deviations below normal, based on regression data from normal populations, this increases the likelihood of stenosis, and may also result in underdevelopment of the corresponding ventricle.

It is also important to evaluate the morphology and function of the valve. The presence of straddling of the tension apparatus of the tricuspid valve (70), even if the aortic and pulmonary roots are abnormally related, does not necessarily rule out a biventricular repair $(20,54)$. The presence of straddling of the mitral valve, in contrast, or a severe mitral valvar abnormality, are probably incompatible with an anatomical repair $(26,54)$. The only situation allowing biventricular repair is when the tension apparatus of the mitral valve inserts to the crest, or on either side, of the muscular ventricular septum. This does not prevent the placement of the intra-ventricular patch, but does risk the anterior leaflet of the valve bulging into the newly created left ventricular outflow tract.

\section{Feasibility of closure of the muscular part of the ventricular septum}

The presence of multiple muscular ventricular septal defects can constitute a serious technical obstacle to achieve a biventricular repair, with the risk of leaving residual intraventricular shunts after surgery.

\section{Presence of distal obstructions in the systemic and pulmonary circulations}

Systemic and pulmonary afterloads have to be normal. Systemic obstructions, such as aortic coarctation and/ or hypoplastic aortic arch, have to be treated in advance. Hypoplastic pulmonary arteries can be a serious contraindication for surgery, as well as elevated pulmonary arterial pressures and resistance.

\section{Feasibility of intra-ventricular repair}

Our approach is predicated on the notion that each individual with double outlet right ventricle is unique, and hence will require a bespoke approach to their management. As emphasized above, in addition to investigating the relationship between the position of the interventricular communication and the great arteries, and the relationship of the arterial roots, it is also necessary to assess the 

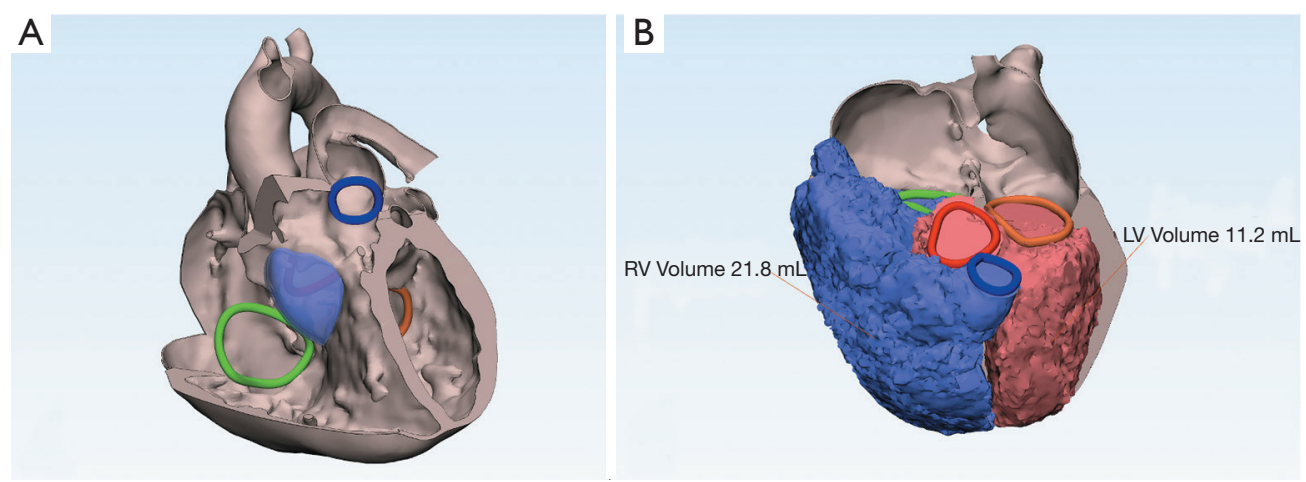

Figure 6 Three-dimensional reconstruction of DORV for operative planning. (A) A preoperative reconstruction of the intracardiac anatomy of a patient with double outlet right ventricle. The location of the anticipated patch has been simulated to provide evidence of the suitability of the planned operative procedure. (B) egmentation of the ventricular volumes as anticipated subsequent to the proposed repair. Dark Blue, pulmonary valvar orifice; Red, aortic valvar orifice; Orange, mitral valvar orifice; Green, tricuspid valvar orifice; Purple (partially transparent), the location of the proposed patch. Further images of this patient are shown in Figure 7.
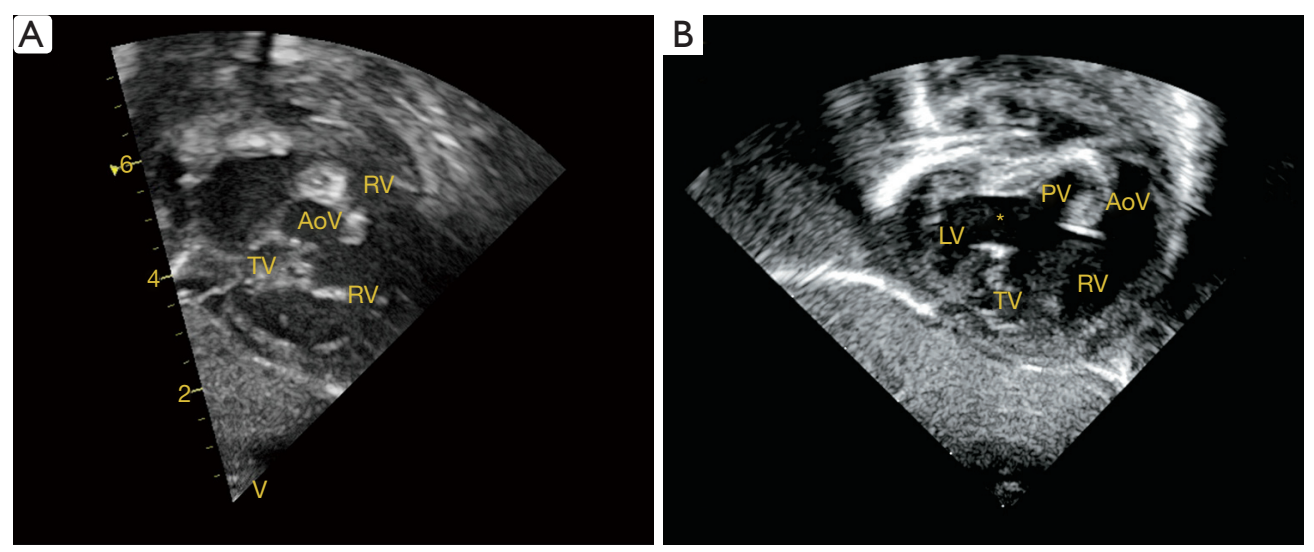

Figure 7 The images show the significance of measuring the distance between the tricuspid and pulmonary valves. (A) The pulmonary valve is distant from the tricuspid valve, whereas the distance is much reduced in the image shown in (B). *, interventricular communication. $\mathrm{LV}$, left ventricle; RV, right ventricle; TV, tricuspid valve; PV, pulmonary valve; AoV, aortic valve.

insertions of the tension apparatus of the atrioventricular valves. These details can all be seen on careful and systematic echocardiographic examination. The key point is to ensure the feasibility of constructing an unobstructed tunnel from the left ventricle to the aorta, while leaving an unobstructed channel from the right ventricle to the pulmonary root. As emphasized, this depends on ensuring an adequate distance between tricuspid and pulmonary valves. Even though the subcostal echocardiographic window usually provides the best views, the distance between the tricuspid and pulmonary valves (which will be the narrowest point of the tunnel to be created from the left ventricle to the aorta) should be assessed from every possible angle. It is usually the case that the intraventricular tunnel is always feasible when the pulmonary valve is supported by an infundibulum (Figure 7). Depending upon the mutual relationship of the great arteries, particularly when the aortic root is anterior to the pulmonary valve orifice, the muscular outlet septum can produce obstruction. In these cases, the outlet septum has to be resected (71).

\section{Surgical technique}

\section{Right ventriculotomy}

The ventriculotomy should began inferiorly, as the orifice 

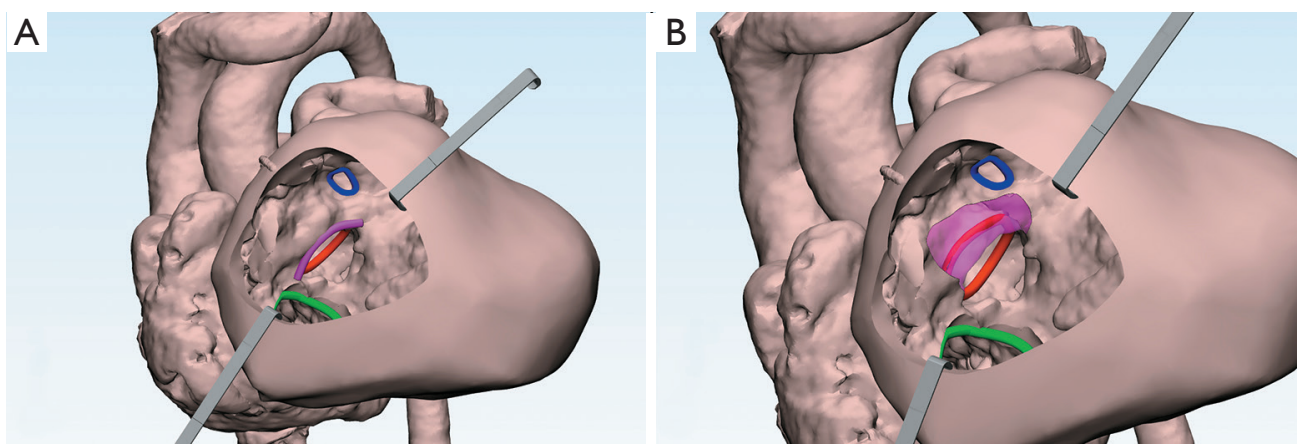

Figure 8 Three-dimensional reconstruction of DORV simulating surgical approach through right ventriculotomy. (A) The view that might be obtained through a right ventriculotomy in the patient shown in Figure 6. (B) The simulated incisions for resection of the muscular outlet septum. Dark Blue, pulmonary valvar orifice; Red, aortic valvar orifice; Green, tricuspid valvar orifice; Pink, outlet septum, with the partially transparent part showing the area to be resected, and the dashed lines showing the potential lines for resection.

of the aortic valve can always be lower than expected from external inspection. The incision is then extended superiorly, keeping the aortic valve under direct vision after opening the right ventricle. The orientation of the incision depends upon the distribution of coronary arteries, along with the planned reconstruction of the right ventricular outflow tract. It is always necessary to obtain adequate exposure of the subaortic area to exclude any anatomical contra-indication to intraventricular repair.

\section{Septal resection}

Resection of the muscular ventricular septum may be required to create an unobstructed tunnel to the aorta should the interventricular communication be restrictive. This is not usually required when the aorta is posterior. Complete resection may be required if the aortic root is anteriorly located, and the septum itself is interposed between the interventricular communication and the aortic valvar orifice. Should it be required, such resection is facilitated by the introduction of a Hegar dilator into the left ventricle, through the orifice of the pulmonary valve. This isolates the outlet septum, and at the same time protects the mitral valve. The resection is performed with three incisions: two parallel to the direction of the aorta, and the third immediately beneath the hinge line of the aortic valvar leaflets (Figure 8). In the presence of straddling tricuspid valve, with insertions to the outlet septum, the septum is not resected, by rather mobilized after the first two incisions. In the rare situations when the interventricular communication opens primarily to the inlet of the right ventricle, anterior enlargement may be required. This is because resection of outlet septum alone will not be not sufficient to create an unobstructed intraventricular tunnel.

\section{Intraventricular tunnel}

When the construction of a straight tunnel is complex, with a high chance of residual or recurrent left ventricular outflow tract obstruction, the alternative options of an arterial switch or REV procedure are safer and easier to perform. Otherwise, the tunnel can be created by placement of a patch. The patch should not be oversized, but rather as short and flat as possible. This is because bulging of the patch will impair left ventricular function, as it will function as an aneurysm, and will also reduce the filling volume of the right ventricle. Potential subaortic obstruction is not prevented by an oversizing the patch, but rather by appropriate resection of the outlet septum. The patch should be trimmed to a diameter corresponding to the distance between the most posterior point of the interventricular communication and the most anterior point of the aortic valve. The edge of the patch is then sutured clockwise, starting from the inferior rim of the defect, where the atrioventricular conduction axis is located. The upper portion of the patch must be very carefully anastomosed around the aortic valvar orifice, leaving adequate space in the subaortic region.

\section{Pulmonary arterial translocation}

In the arterial switch or REV procedure, the pulmonary 
trunk and its branches must be fully mobilized, extending beyond the pericardial reflections. This is required either to attach the distal stump of the pulmonary artery onto the original proximal aorta when performing the arterial switch, or onto the right ventriculotomy in the REV procedure. This surgical step must be tailored to the specific relationship between the great arteries, and will depend on whether the Lecompte manoeuvre is to be performed. It is not strictly necessary when the great arteries are side-byside, nor in the rare situations when the pulmonary trunk is located slightly anterior to the aorta. If the Lecompte procedure is required, then the transection of the aorta and of the pulmonary trunk immediately above the insertions of the valvar leaflets is performed at the beginning of the operation. This facilitates the exposure of the intracardiac anatomy, and the introduction of surgical instruments through the arterial valvar orifices. As already discussed and described, the ascending aorta is shortened and the right ventricular outflow tract reconstructed.

\section{"En bloc" rotation of the arterial roots}

In the recent years, it has been appreciated that it is often possible to achieve "en bloc" rotation of the outflow tracts (72). This option must now always be considered for patients with double outlet right ventricle, since it can allow for complete anatomic repair in seemingly difficult situations. The procedure is advantageous in allowing for growth of all tubular structures, and in appropriate cases permitting preservation of the native pulmonary valve (73-76). The technique (77), furthermore, is not affected by the size and location of the interventricular communication. It is ideally performed when the ratio of the diameters of the pulmonary and aortic roots is between 0.3 and 0.8 . The procedure (73-77) is performed by transecting the intrapericardial aorta and pulmonary trunk at the same level, with excision of a short segment of the ascending aorta. Both coronary arteries are excised after extensive mobilization, and both arterial roots are liberated from the base of the ventricular mass. The outlet septum is divided, preserving the medial papillary muscle. The excised outflow tracts are then rotated through $180^{\circ}$ and reimplanted. The interventricular communication, which is the outflow tract for the left ventricle, is tunnelled to the aortic root, followed by reimplantation of the coronary arteries. The Lecompte maneuver is performed, and the aortic root and ascending aorta are anastomosed end-toend. The anastomosis between the pulmonary root and right ventricular outflow tract is completed, if necessary with a subvalvar patch plasty or transannular patch, completing the procedure with an additional end-to-end anastomosis between the pulmonary root and the pulmonary trunk.

\section{Conclusions}

The need for an individualized surgical approach in individuals with both arterial trunks arising from the morphologically right ventricle is dictated by the extreme morphological variability encountered in this setting, with each patient being unique. To date, meaningful comparison between different reported surgical series has been difficult because of the variable distribution of individuals, and the lack of reports of specific surgical approaches for wellcategorized groups of patients. Our approach, being tailored to each specific cardiac morphology, can be offered to any patient with this ventriculo-arterial connection. Given the difficulties of diagnosis, and the multiple therapeutic indications, very close collaboration between cardiologists and surgeons is indispensable if further progress is to emerge in the understanding and management of this complex congenital cardiac lesion.

Our review has considered all morphologic variants of the double outlet right ventricle and the potential surgical options available. The main limitation of our research was the absence of a series of patients operated on using the described surgical approaches. Future research should collect large series of patients with this heart malformation and match the used surgical approaches with the outcomes to validate our proposal.

\section{Acknowledgments}

Funding: None.

\section{Footnote}

Reporting Checklist: The authors have completed the Narrative Review reporting checklist. Available at http:// dx.doi.org/10.21037/tp-20-227

Peer Review File: Available at http://dx.doi.org/10.21037/ tp-20-227

Conflicts of Interest: All authors have completed the ICMJE uniform disclosure form (available at http://dx.doi. org/10.21037/tp-20-227). Dr. AFC serves as an unpaid 
editorial board member of Translational Pediatrics from April 2020 to March 2022. The authors have no other conflicts of interest to declare.

Ethical Statement: The authors are accountable for all aspects of the work in ensuring that questions related to the accuracy or integrity of any part of the work are appropriately investigated and resolved.

Open Access Statement: This is an Open Access article distributed in accordance with the Creative Commons Attribution-NonCommercial-NoDerivs 4.0 International License (CC BY-NC-ND 4.0), which permits the noncommercial replication and distribution of the article with the strict proviso that no changes or edits are made and the original work is properly cited (including links to both the formal publication through the relevant DOI and the license). See: https://creativecommons.org/licenses/by-nc-nd/4.0/.

\section{References}

1. Kirklin JW, Harp RA, McGoon DC. Surgical treatment of origin of both vessels from the right ventricle, including cases of pulmonary stenosis. J Thorac Cardiovasc Surg 1964;48:1026-36.

2. Wilcox BR, Ho SY, Macartney FJ, et al. Surgical anatomy of double-outlet right ventricle with situs solitus and atrio-ventricular concordance. J Thorac Cardiovasc Surg 1981;82:405-17.

3. Walters HL III, Mavroudis C, Tchervenkov CI, et al. Congenital heart surgery nomenclature and database project: double outlet right ventricle. Ann Thorac Surg 2000;69:S249-63.

4. Ebadi A, Spicer DE, Backer CL, et al. Double-outlet right ventricle revisited. J Thorac Cardiovasc Surg 2017;154:598-604.

5. Lev M, Bharati S, Meng CC, et al. A concept of doubleoutlet right ventricle. J Thorac Cardiovasc Surg 1972;64:271-81.

6. Anderson RH, McCarthy K, Cook AC. Double outlet right ventricle. Cardiol Young 2001;11:329-44.

7. Pang K, Meng H, Wang H, et al. Value of a novel categorization of congenital double-outlet right ventricle on guiding the choice of surgical approaches. Zhonghua Xin Xue Guan Bing Za Zhi 2015;43:969-74.

8. Van Praagh R. What determines whether the great arteries are normally or abnormally related? Am J Cardiol 2016;118:1390-8.
9. Bharucha T, Hlavacek AM, Spicer DE, et al. How should we diagnose and differentiate hearts with double-outlet right ventricle?. Cardiol Young 2017;27:1-15.

10. Wang C, Chen S, Zhang H, et al. Anatomical classification of the coronary arteries in complete transposition of the great arteries and double outlet right ventricle with subpulmonary ventricular septal defect. Thorac Cardiovasc Surg 2017;65:26-30.

11. Spadotto V, Frescura C, Ho SY, et al. The concept of double inlet-double outlet right ventricle: a distinct congenital heart disease. Cardiovasc Pathol 2017;26:39-44.

12. Talwar S, Anderson RH, Bhoje A, et al. Double Outlet Right Ventricle With Right-Sided Aorta From the LeftSided Morphologically Right Ventricle in the Setting of Discordant Atrioventricular Connections. World J Pediatr Congenit Heart Surg 2020;11:NP72-76.

13. Lu CX, Wang W, Wang Q, et al. A novel MEF2C loss-offunction mutation associated with congenital double outlet right ventricle. Pediatr Cardiol 2018;39:794-804.

14. Goo HW. Coronary artery anomalies on preoperative cardiac CT in children with tetralogy of Fallot or Fallot type of double outlet right ventricle: comparison with surgical findings. Int J Cardiovasc Imaging 2018; doi: 10.1007/s10554-018-1422-1.

15. Bex JP, Lecompte Y, Baillot F, et al. Anatomical correction of transposition of the great arteries. Ann Thorac Surg 1980;29:86-8.

16. Nikaidoh H. Aortic translocation and biventricular outflow tract reconstruction. A new surgical repair for transposition of the great arteries associated with ventricular septal defect and pulmonary stenosis. J Thorac Cardiovasc Surg 1984;88:365-72.

17. Lecompte Y, Bex JP. Repair of transposition of the great arteries, ventricular septal defect and left ventricular outflow tract obstruction. J Thorac Cardiovasc Surg 1985;90:151-2.

18. Sakata R, Lecompte Y, Batisse A, et al. Anatomical repair of anomalies of ventriculo-arterial connection associated with ventricular septal defect. I: Criteria for surgical decision. J Thorac Cardiovasc Surg 1988;95:90-5.

19. Borromée L, Lecompte Y, Batisse A, et al. Anatomic repair of anomalies of ventriculo-arterial connection associated with ventricular septal defect. II: Clinical results in 50 patients with pulmonary outflow tract obstruction. J Thorac Cardiovasc Surg 1988;95:96-102.

20. Serraf A, Nakamura T, Lacour-Gayet F, et al. Surgical approaches for double-outlet right ventricle or transposition of the great arteries associated with 
straddling atrioventricular valves. J Thorac Cardiovasc Surg 1996;111:527-35.

21. Delius RE, Rademecker MA, De Leval MR, et al. Is a high risk biventricular repair always preferable to conversion to single ventricle repair? J Thorac Cardiovasc Surg 1996;112:1561-8.

22. Brown JW, Ruzmetov M, Okada Y, et al. Surgical results in patients with double outlet right ventricle: a 20-year experience. Ann Thorac Surg. 2001;72:1630-5.

23. Cetta F, Boston US, Dearani JA, et al. Double outlet right ventricle: opinions regarding management. Curr Treat Options Cardiovasc Med. 2005;7:385-90.

24. Morell VO, Jacobs JP, Quintessenza JA. Aortic translocation in the management of complex transposition of the great arteries with ventricular septal defect and pulmonary stenosis: results and follow-up. Ann Thorac Surg 2005;79:2089-92.

25. Bautista-Hernandez V, Marx GR, Bacha EA, et al. Aortic root translocation plus arterial switch for transposition of the great arteries with left ventricular outflow tract obstruction: intermediate-term results. J Am Coll Cardiol 2007;49:485-90.

26. Bradley TJ, Karamlou T, Kulik A, et al. Determinants of repair type, reintervention, and mortality in 393 children with double-outlet right ventricle. J Thorac Cardiovasc Surg. 2007;134:967-73.e6.

27. Yeh T, Ramaciotti C, Leonard SR, et al. The aortic translocation (Nikaidoh) procedure: midterm results superior to the Rastelli procedure. J Thorac Cardiovasc Surg 2007;133:461-9.

28. Hu SS, Liu ZG, Li SJ, et al. Strategy for biventricular outflow tract reconstruction: Rastelli, REV, or Nikaidoh procedure? J Thorac Cardiovasc Surg 2008;135:331-8.

29. Lacour-Gayet F. Intracardiac repair of double outlet right ventricle. Semin Thorac Cardiovasc Surg Pediatr Card Surg Annu 2008;11:39-43.

30. Li S, Ma K, Hu S, Hua Z, et al. Biventricular repair for double outlet right ventricle with non-committed ventricular septal defect. Eur J Cardiothorac Surg 2015;48:580-7.

31. Villemain O, Belli E, Ladouceur M, et al. Impact of anatomic characteristics and initial biventricular surgical strategy on outcomes in various forms of double-outlet right ventricle. J Thorac Cardiovasc Surg 2016;152:698-706.e3.

32. Menon S, Kumar CJ, Mathew T, et al. Double outlet right ventricle with intact ventricular septum: avulsion or exclusion? World J Pediatr Congenit Heart Surg 2016;7:220-2.
33. Furlanetto G, Furlanetto BH, Teixeira EM, et al. Double root switch repair for Taussig-Bing anomaly. World J Pediatr Congenit Heart Surg 2016;7:367-71.

34. Wu Q, Jin Y, Li H, et al. Surgical treatment for double outlet right ventricle with pulmonary outflow tract obstruction. World J Pediatr Congenit Heart Surg 2016;7:696-9.

35. Villemain O, Bonnet D, Houvel L, et al. Double outlet right ventricle with non-committed ventricular septal defect and two adequate ventricles: is anatomical repair advantageous? Semin Thorac Cardiovasc Surg 2016;28:69-77.

36. Backer CL. Double outlet right ventricle: where are we now? Semin Thorac Cardiovasc Surg 2016;28:79-80.

37. Lee HP, Bang JH, Baek JS, et al. Aortic root translocation with arterial switch for transposition of the great arteries or double outlet right ventricle with ventricular septal defect and pulmonary stenosis. Korean J Thorac Cardiovasc Surg 2016;49:190-4.

38. Kwaśniak E, Haponiuk I, Chojnicki M, et al. Right ventricular outflow tract stenting in double outlet right ventricle with critical pulmonary stenosis and hypoplastic pulmonary arteries. Postepy Kardiol Interwencyjnej 2016;12:267-70.

39. Wu QY, Li DH, Li HY, et al. Surgical treatment of double outlet right ventricle complicated by pulmonary hypertension. Chin Med J (Engl) 2017;130:409-13.

40. Meng H, Pang KJ, Li SJ, et al. Biventricular repair of double outlet right ventricle: preoperative echocardiography and surgical outcomes. World J Pediatr Congenit Heart Surg 2017;8:354-60.

41. Morell VO. Nikaidoh procedure: how I teach it. Ann Thorac Surg 2017;104:1446-9.

42. Anwar S, Singh GK, Miller J, et al. 3D printing is a transformative technology in congenital heart disease. JACC Basic Transl Sci 2018;3:294-312 .

43. Garekar S, Bharati A, Chokhandre M, et al. Clinical application and multidisciplinary assessment of three dimensional printing in double outlet right ventricle with remote ventricular septal defect. World J Pediatr Congenit Heart Surg 2016;7:344-50.

44. Dydynski PB, Kiper C, Kozik D, et al. Three-dimensional reconstruction of intracardiac anatomy using CTA and surgical planning for double outlet right ventricle: early experience at a tertiary care congenital heart center. World J Pediatr Congenit Heart Surg 2016;7:467-74.

45. Speggiorin S, Durairaj S, Mimic B, Corno AF. Virtual 3D Modeling of Airways in Congenital Heart Defects. Front Pediatr. 2016;4:116. 
46. Bhatla P, Tretter JT, Ludomirsky A, et al. Utility and scope of rapid prototyping in patients with complex muscular ventricular septal defects or double-outlet right ventricle: does it alter management decisions? Pediatr Cardiol 2017;38:103-14

47. Yoo SJ, van Arsdell GS. 3D Printing in Surgical Management of Double Outlet Right Ventricle. Front Pediatr. 2018;5:289.

48. Zhao L, Zhou S, Fan T, et al. Three-dimensional printing enhances preparation for repair of double outlet right ventricular surgery. J Card Surg 2018;33:24-7.

49. Yim D, Dragulescu A, Ide H, et al. Essential modifiers of double outlet right ventricle revisit with endocardial surface images and 3-dimensional print models. Circ Cardiovasc Imaging 2018;11:e006891.

50. Hoashi T, Ichikawa H, Nakata T, et al. Utility of a super-flexible three-dimensional printed heart model in congenital heart surgery. Interact Cardiovasc Thorac Surg 2018. doi: 10.1093/icvts/ivy160.

51. Yang Y, Wang J, Quiao A, et al. Numerical simulation of the influence of geometric configurations on pressure difference in the intraventricular tunnel. Front Physiol 2020;11:133. doi: 10.3389/fphys.2020.00133.

52. Kariya T, Washio T, Okada JI, et al. Personalized perioperative multi-scale, multi-physics heart simulation of double outlet right ventricle. Ann Biomed Eng 2020. doi: 10.1007/s10439-020-02488-y.

53. Reploge RL, Campbell DJ, Campbell DC. Double outlet ventricles. In Arciniegas E (ed.): Pediatric cardiac surgery. Chicago, Year Book Medical Publishers Inc., 1985:231-45.

54. Lecompte Y, Batisse A, Di Carlo D. Double-outlet right ventricle: surgical synthesis. Adv Card Surg 1993;4:109-36.

55. Lu T, Li J, Hu J, et al. Biventricular repair of doubleoutlet right ventricle with noncommitted ventricular septal defect using intraventricular conduit. J Thorac Cardiovasc Surg 2020;159:2397-403.

56. Rastelli GC. A new approach to anatomic repair of transposition of the great arteries. Mayo Clin Proc 1969;44:1.

57. Lecompte Y. Rastelli repair for transposition of the great arteries: still the best choice? J Thorac Cardiovasc Surg 2002;123:192-3.

58. Lecompte Y, Neveux JY, Leca F, et al. Reconstruction of the pulmonary outflow tract without prosthetic conduit. J Thorac Cardiovasc Surg 1982;84:727-33.

59. Rubay J, Lecompte Y, Batisse A, et al. Anatomic repair of anomalies of ventriculo-arterial connection (REV). Eur J Cardiothorac Surg 1988;2:305.
60. Kim YJ, Park JJ, Lee JR, et al. Modified Lecompte procedure for the anomalies of ventriculoarterial connection. Ann Thorac Surg 2001;72:176-80; discussion 180-1.

61. Di Carlo D, Tomasco B, Cohen L, et al. long-term results of the REV (reparation à l'étage ventriculaire) operation. J Thorac Cardiovasc Surg 2011;142:336-43.

62. Al-Jughiman MK, Al-Omair MA, Van Arsdell GS, et al. D-transposition of the great arteries with ventricular septal defect and left ventricular outflow tract obstruction (D-TGA/VSD/LVOTO): a survey of perceptions, preferences, and experience. Pediatr Cardiol 2015;36:896-905.

63. Russo P, Danielson GK, Puga FJ, et al. Modified Fontan procedure for biventricular hearts with complex forms of double-outlet right ventricle. Circulation 1988;78:III20-5.

64. Day R, Laks H, Milgalter E, et al. Partial biventricular repair for double-outlet right ventricle with left ventricular hypoplasia. Ann Thorac Surg 1990;49:1003-5.

65. Ruzmetov M, Rodefeld MD, Turrentine MW, et al. Rational approach to surgical management of complex forms of double outlet right ventricle with modified Fontan operation. Congenit Heart Dis 2008;3:397-403.

66. Lacour-Gayet F. Management of older single functioning ventricles with outlet obstruction due to a restricted "VSD" in double inlet left ventricle and in complex double outlet right ventricle. Semin Thorac Cardiovasc Surg Pediatr Card Surg Annu 2009;12:130-2.

67. Corno AF. Surgical treatment of complex cardiac anomalies: the "one and half ventricle repair". Eur J Cardiothorac Surg 2002;22:436-7.

68. Corno AF. Borderline left ventricle. Eur J Cardiothorac Surg 2005;27:67-73.

69. Oladunjoye O, Piekarski B, Baird C, et al. Repair of double outlet right ventricle: midterm outcomes. J Thorac Cardiovasc Surg 2019;159:254-64.

70. Tabry IF, McGoon DC, Danielson GK, et al. Surgical management of straddling atrio-ventricular valve. J Thorac Cardiovasc Surg 1979;77:191-201.

71. Kawashima Y, Fugita T, Miyamoto T, et al. Intraventricular rerouting of blood for the connection of Taussig-Bing malformation. J Thorac Cardiovasc Surg 1971;62:825-9.

72. Anderson RH. Rotation of the ventricular outflow tracts. Eur J Cardiothorac Surg 2016;50:585.

73. Mair R, Sames-Dolzer E, Vondrys D, et al. En bloc rotation of the truncus arteriosus-an option for anatomic repair of transposition of the great arteries, ventricular septal defect, and left ventricular outflow tract obstruction. 
J Thorac Cardiovasc Surg 2006;131:740-1.

74. Mair R, Sames-Dolzer E, Innerhuber M, et al. Anatomic repair of complex transposition with en bloc rotation of the truncus arteriosus: 10-year experience. Eur J Cardiothorac Surg 2016;49:176-82.

75. Lee JU, Jang WS, Lee YO, et al. Long-term follow-up of the half-turned truncal switch operation for transposition of the great arteries with ventricular septal defect and pulmonary stenosis. Korean J Thorac Cardiovasc Surg 2016;49:112-4.

Cite this article as: Corno AF, Durairaj S, Skinner GJ. Narrative review of assessing the surgical options for double outlet right ventricle. Transl Pediatr 2021;10(1):165-176. doi: 10.21037/tp20-227
76. Nomura K, Yamagishi M, Yamamoto Y, et al. Half-turned truncal switch operation for single coronary in a patient with transposition of the great artery and pulmonary stenosis. J Thorac Cardiovasc Surg 2017;154:268-70.

77. Yamagishi M, Shuntoh K, Matsushita T, et al. Half-turned truncal switch operation for complete transposition of the great arteries with ventricular septal defect and pulmonary stenosis. J Thorac Cardiovasc Surg 2003;125:966-8. 